\title{
Connections: Participatory art as a factor for social cohesion
}

\author{
Oliver Mag Gingrich \\ National Centre for Computer \\ Animation, London, UK \\ olivergingrich@gmail.com
}

Alain Renaud

Bournemouth University

Geneva, Switzerland

Alain.renaud@mintlab.ch

\author{
Paola D'Albore \\ Independent Author \\ London, UK \\ paoladalbore@gmail.com
}

\author{
Evgenia Emets \\ Artist \\ Ericeira, Portugal \\ Emetsjane@gmail.com \\ David Negrao \\ Artist \\ Lisbon, Portugal \\ davidnegra@gmail.com
}

\begin{abstract}
The potential for participatory arts to contribute to mental health and wellbeing has been subject of parliamentary debates, all-party interparliamentary reports, research by the Arts Council of England, as well as academic research. Often, these questions stand in the light of accountability of Art, of measurable societal benefit, not at least to justify funding decisions and institutional support. Criticism of this quantitative reading of participatory arts centres around limitations in measuring social connectedness and its benefits, as well as other side-effects of reductionism (Bishop 2012). This paper presents four recent media arts projects aiming to contribute to social cohesion through a multitude of strategies. This paper discusses the potential of media arts to contribute to social connectedness as well as challenges in measuring their success.
\end{abstract}

Media art. Participatory art. Art and health. Art and wellbeing.

\section{INTRODUCTION}

Side effects of constant urbanisation, rapid growth and modernisation are not only limited to the environment itself, but also impact quality of life, communal living and wellbeing. Participatory art has a role to play in bringing communities together, in raising awareness for pressing issues of our time and assuring that those impacted are supported in finding strategies to help themselves. This paper discusses the potential for participatory art forms to trigger discussions around community, and to contribute to social cohesion focusing on three case studies:

After the Grenfell fire in North Kensington on the 14th of June 2017, participatory art played a key role in bringing communities together. AYAH - Sign an exhibition on Islamic Digital Art by ART IN FLUX in collaboration with Sara Choudhrey provided a forum for local community members to collaborate.

The piece The Crack invites audience members to reflect on the role of concrete as a key polluter and CO2 emitter. Using an EEG headset the audience is invited to concentrate thereby affecting visual representations of a crack in the concrete structure. The playful engagement raises awareness for a major environmental issue of our time while bringing communities closer together.

KIMA: Noise, a participatory art project by the Analema Group in collaboration with Prof. Stephen Stansfeld raises awareness for the impact of noise on health and wellbeing. Embedded into a framework of discussions, public talks, workshops and a film, the art project facilitates discussions for change, through a number of different strategies. Most of all, local communities are invited to think together on how they can contribute to change.

The project KIMA: Voice brings communities together through participatory art, offering an interface for collaborative sound and music making, and harmonisation. The project was displayed at the Great Exhibition Road Festival at Imperial College in June 2019, and its effect on 'social connectedness' was measured with the help of the HEartS Study by the Centre for Performance Science, a joint research centre between Imperial College and the Royal College of Music.

Together these four projects highlight the potential for technology facilitated art to influence society through a positive impact on social connectedness through new connections. 


\section{TECHNOLOGY \& SOCIETY}

The impact of new digital technologies on individual and society is nowadays a widely debated topic that considers the potentiality of augmenting human abilities while at the same time holding sway on how we perceive and make sense of the world around us, for better or for worse.

Technology has become so pervasive and an essential element of our everyday life that it is hard to deny its decisive impact on our sensible experience to the point where, according to its most convinced critics, it is believed to function as a tool to provide capitalism with new modes of abstracting the body from its whole concreteness. This is more and more evident with the transition of capitalism from industry producing goods and services towards contemporary post-industrial immaterial structures producing signs, syntax and subjectivity, and with the exploitation of digital technology for the collection and accumulation of huge amount of personal data in order to predict people's behaviours for profit purposes.

New media art made its appearance following the rise of the digital revolution and, since its inception, it has been exploring all the potentialities offered by the new technologies. It is particularly interesting the shift of the focus from the symbolic plane to the device itself: new media artists begun to interrogate themselves on the very nature of new technologies, hardware and software, and on the manifold ways they can affect society in its entirety. They revealed how our new capacity for ceaseless communication, countless information and heightened senses is two-faced: from empowerment and emancipation to control and abstraction.

New media artists have shown that interactive and immersive digital art practices make use of technology in an alternative way to that of capitalism and can be deemed as forms of resistance to the emptying abstracted existence, typical of the individual reduced to data and information. The intrinsic capacity of those practices for enhanced user participation brings about a return to the body and to perceptual-based experiences, fostering new forms of interaction and non-linear thinking. This leads to an overturning of the role of the individual, who is turning from passive viewer to active participant and co-creator of the artwork.

The interrelation between individual-group-machine offers various existential possibilities for the creation of something new, beyond the repeatable and identical structures of the typical production of subjectivity under contemporary capitalism.
Digital technologies have been subjected to new forms of control and to social and individual segmentation and atomisation while, at the same time, enhancing the potential for new forms of interaction and engagement that can lead to creating new experiences and content for active audiences.

In the 90's, with interactive technologies growing exponentially, artists begun to explore the basis of social participation and interaction while technological mediation became a crucial component of social interactions in participatory art projects. Since its inception, participatory art affirmed the active role of audiences in the creation of the artwork stressing the importance of events and processes that engender social interactions, thus moving away from an exclusive focus on defined and delineated art objects. Both digital technologies and participatory art practices focus on participation and interaction, opening up the disciplinary boundaries of art. This generates an increasing convergence between participation, art and digital technology, and deepens an exploration of notions of collaboration and community within the arts.

The three case studies here presented offer some examples of how productive the intersection between digital art and participatory art could be. These projects aims to raise awareness for pressing societal issues working directly with local residents, local authority and art institutions in order to open up a discussion that helps to build connections and bring people together as well as it stimulates to find out individual and communal strategies to tackle pressing issues in their environment. Technological tools used in the art projects facilitate awareness of how and why those issues are critical through heightening subjective perceptions and building up a collective understanding supporting citizen empowerment in the decision-making process.

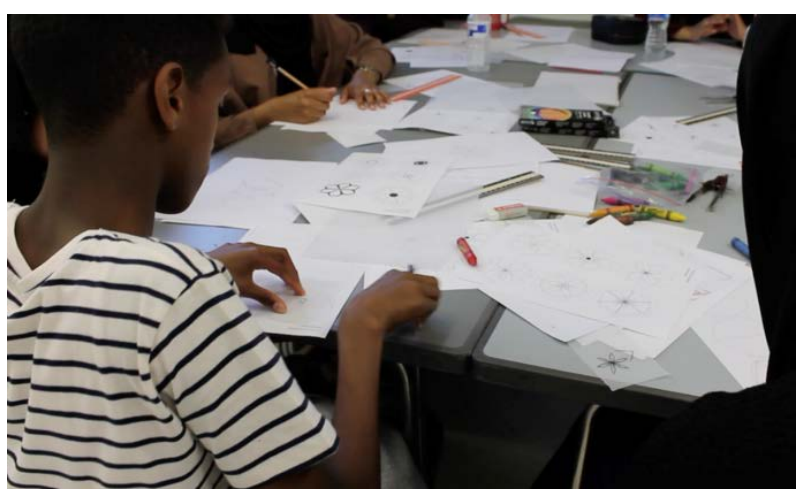

Figure 1: AYAH - Sign - workshop with Sara Choudhrey. 


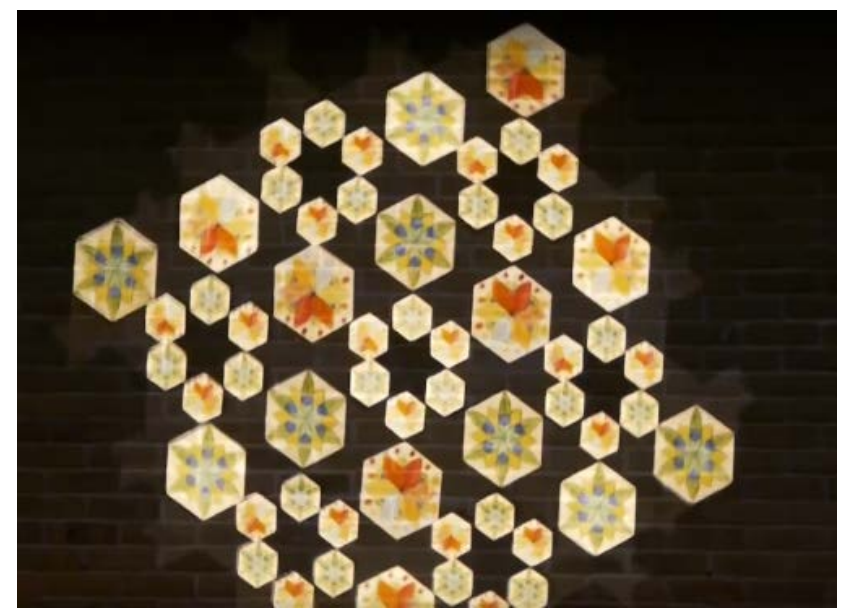

Figure 2: AYAH - Sign projected onto Kensington Leisure Centre, June 2018.

\section{AYAH - SIGN}

Coinciding with the one-year anniversary of the Grenfell tragedy, Oliver Gingrich of ART IN FLUX and artist Sara Choudhrey curated a series of workshops and events as part of the $A Y A H$ - Sign project. Members of the local community and general public were invited to explore new forms of artistic practice with a focus on Islamic patternmaking, contributing towards a collaborative community digital artwork.

Orchestrated by London based artist platform ART IN FLUX, audiences of all ages primarily from the North Kensington area took part in workshops developed to provide an understanding of Islamic art and the production methods for patterns from Islamic visual culture, including geometric and floral motif design.

Dr. Sara Choudhrey's art practice centres around Islamic Digital Art, using a combination of elaborate digital and analogue techniques to create complex floral and arabesque patterns. Her art pieces, which were exhibited alongside established media artists Ben Johnson and Zara Hussain at the $A Y A H$ Exhibition, often make use of wood cutting techniques, presenting complex visual patterns inspired by Islamic Art. Dr. Sara Choudhrey developed a workshop format, which allowed local audiences of all ages to gain an understanding of some of the fundamental methods and techniques of Islamic artistic practices. In four sessions, audiences learned how to create their own, personal Islamic art inspired drawings. These drawings were subsequently digitised, and animated by Dr. Oliver Gingrich to contribute to a collaborative artwork.

The results were a collaborative digital animation artwork, where artists Sara Choudhrey and Oliver Gingrich combined their practice with the creative outcomes of the local community. The animation was exhibited as a public installation alongside further artworks by established media artists at ACAVA's Maxilla Space, and shared with a wider public audience on site alongside the Grenfell tower, at the Kensington Leisure Centre.

The aims of this project were to break down barriers between local audiences and perceptions around contemporary media art whilst also providing an insight into digital art practice. The project also benefited from making art spaces more welcoming and portraying this as an accessible creative space for all. Social connectedness, i.e. the experience of belonging and relatedness between people (Van Bel et al. 2009), is becoming an increasingly important concept in the discussion of social benefits of media including participatory art practices (Bennington et al. 2016).

More importantly, the workshop as well as the following exhibition, broke down barriers between established media artists (Ben Johnson, Sara Choudhrey and Zara Hussain), while providing a forum for the members of the Grenfell community to come together, to contemplate, commemorate and reflect through artistic practices. Art as a vehicle for social engagement, a forum for local communities to come together, to collaborate, to engage with one another creatively, but also to learn about cultural practices, serves a societal function that is hard to measure. The workshop and exhibition was orchestrated around the one-year anniversary of one of the most terrible tragedies in recent London history, the Grenfell fire, in which more than 70 people lost their lives. In a situation, where it is hard for those affected, to find words to deal with grief, anger, sadness, loss and memory, art can help to provide a framework for communities to come together.

With $A Y A H$ - Sign, Sara Choudhrey and Oliver Gingrich wanted to send a sign to local communities. The piece was projected every evening that the exhibition took place, opposite the ruins of the tower on the façade of Kensington Leisure centre, which kindly offered their support. For 4 hours each evening, passers-by could see the collaborative art piece created by local communities, a digital mosaic, a collection of creative engagements drawn by over 60 workshop participants, members of the local community. The social benefit of art as a forum for community members coming together in a time of need, is hard to quantify. AYAH - Sign was not profitable, and yet the piece has received recognition, by the Council who supported the initiative and exhibited it at the Kensington and Chelsea town hall almost a year later, by Arts Council England, who funded it, Portobello film festival, that exhibited it to thousands of viewers, and by Ars Electronic 
Festival, where it has been nominated for a Prix Ars Electronica. The question remains, can we, should we, do we need to quantify the evaluation of such a participatory practice and if so to what end?

\section{THE CRACK}

Intelligent Matter was an exhibition and workshop activity by Stuart F. Batchelor and Oliver Gingrich, which took place a year after $A Y A H$ - Sign at Maxilla Space near the Grenfell tower, in North Kensington. The activity coincided with the second year anniversary of the Grenfell tragedy. The topic of the exhibition 'Intelligent Matter' was conceptually positioned to raise interest into new media art forms, new materials, new practices, but also in the potential of media art, to change the way we think about traditional art forms such as painting.

Stuart F. Batchelor's practice is making use of his own developed algorithms, which allow him to animate traditional drawings into novel interpretations that can be exhibited as prints, digital artworks or as animation.

Oliver Gingrich's practice on the other hand often involves brainwave interfaces. For intelligent matter, three different installations invited the audience to use their concentration to engage with the artwork. Whereas 'Aura' (2019) invites audiences to listen to their own thoughts (Gingrich 2019), Memoria is a piece about commemoration.

Audiences are invited to remember their loved ones, a neighbour they might have lost, by looking at a canvas, while their thoughts materialise as a subtly changing stream of colour. The piece was first exhibited a week after the fire, at Maxilla Space, and remained relevant a year due to the vicinity of the exhibition to the Grenfell site as well as the invited audience, predominantly members of the local community.

The Crack (Gingrich 2019) is an EEG controlled projection piece that invites the audience to create cracks in concrete structures that surround them, using their concentration. Maxilla space is a concrete building situated underneath the Westway flyover, itself a giant concrete structure.

Concrete and cement are one of the top pollutants in the world. By cracking up concrete structures we allow its surface to absorb sulphur toxins in the air, concrete turns into a material that can help to absorb air pollution. Researchers at the Stony Brooks University in New York discovered that concrete, when broken up, can absorb sulphur particles. The audience is actively invited to use their concentration to create cracks in the concrete structure that surrounds them. This gamified experience, invites audiences to use their brain power, to 'grow' the cracks in the wall, projected onto the concrete building in front of them.

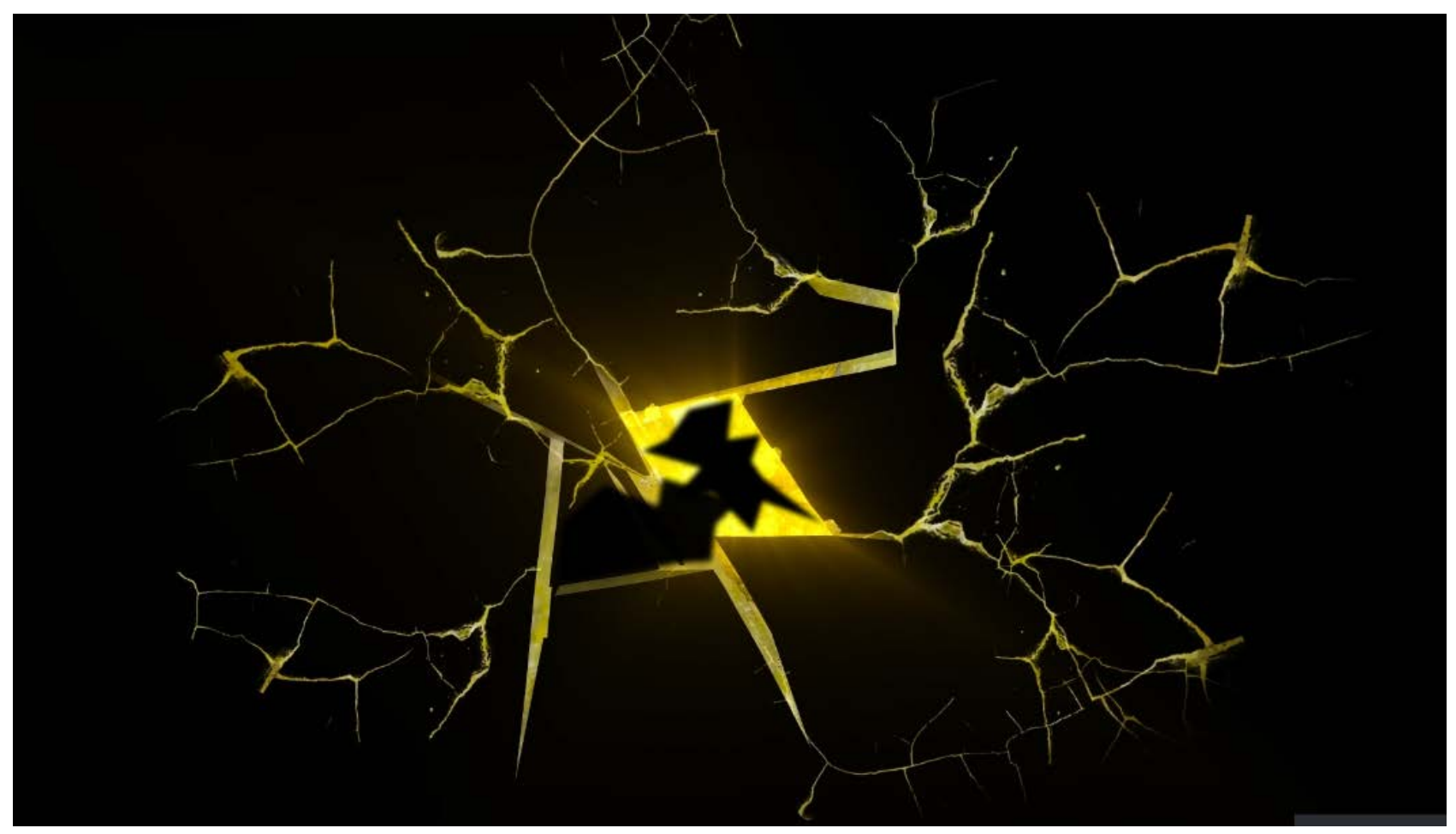

Figure 3: The Crack, Brainwave Art piece, Oliver Gingrich 2019. 
The projected visual representation depicts sulphur crystals, created through generative adversarial networks (GANs) using machine learning algorithms. The higher the concentration, the larger the crack. Recent research shows the role cement can play in absorbing sulphur pollution, an effect that is heightened if the surface is porous or broken up. Playfully, the audience can take part in reversing the role of cement as global key polluter. The installation was framed by news articles on the research surrounding concrete. The exhibition was visited by KAA Aldridge Academy, and art school that was directly affected by the Grenfell fire. The involvement, direct engagement and interest by the students validates the piece's conceptual complexity.

Students at KAA Aldridge spent a good hour with the piece, making the 'Crack' in the Wall grow larger, as their concentration was measured by the EEG headset, thereby driving the cracks in the wall.

Whenever concentration drops below a certain threshold, the crack disappears, and participants have to trigger the crack from scratch. This mechanism supports a sustained concentration, something that is easier to achieve for students than teachers, spiking a new form of competition in the classroom. More than the gamified experience, the students showed interest in the conceptual background of the piece, it's raison d'etre.

Directly affected by the $\mathrm{CO} 2$ emissions of the nearby Westway flyover, the subject of air pollution remains relevant in dense urban environments such as North Kensington, and students showed an active interest in methods to reduce air pollution.

Like $A Y A H$, a year earlier, the intelligent matter exhibition offered a mixture of workshops, participatory art, and discussions around the art pieces to local audiences. The benefit of the work lied in its potential to trigger important societal discussions, in providing a forum for reflection and collaborative creative engagement. Although the exhibition was only visited by several hundred visitors, the focus of the work contributed to a wider debate that helps to raise awareness for important global and local issues of urbanisation. The participatory character of the activity assures that reflective processes are verbalised, critically questioned and collective answers are being pursued.

The question remains, how can we capture, and record the impact of such activities to inform future funding decisions? Can such participatory art engagements contribute to a sense of social cohesion, inter-connectedness and sense of community?

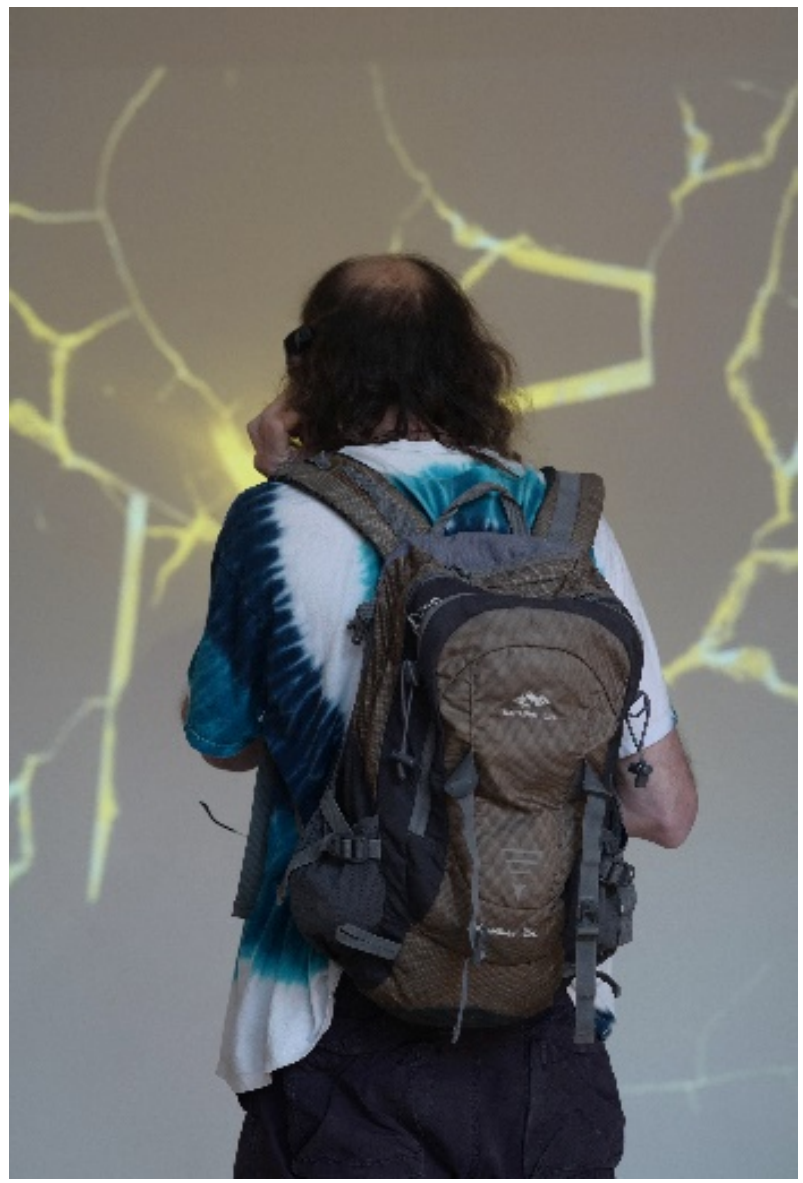

Figure 4: The Crack, Intelligent Matter Exhibition at ACAVA's Maxilla Space image by Sophie le Roux (http://www.sophielerouxdocu.com).

\section{KIMA: NOISE}

How do urban noises affect our physical, mental and emotional wellbeing?

The art collective Analema Group explores the effects of urban noise through participatory art combining novel interaction techniques with a geometric sound sculpture, large-scale, real-time projection and live streaming of urban noise from around the city of London.

Following a year-long development with the researcher and noise expert Prof. Stephen Stansfeld (Queen Mary University of London), the installation KIMA: Noise presented the outcome of this collaboration between research and cuttingedge, participatory art at Tate Exchange, at Tate Modern to the London public. The project brought together scientists and artists with local communities and the general public to open a discourse on the impact of noise on health and wellbeing.

A pilot of the project was shown in September 2019 at Maxilla Space, in North Kensington, with the 
sounds from the Westway streaming into the gallery space. Members of local communities were invited to experience the art installation but also to take part in the workshop, sharing their experiences of noise and exploring creative strategies of dealing with the urban noise.

At Tate Exchange KIMA: Noise, ran alongside a rich programme of activities to explore urban noises through participatory art, talks, a performance and a workshop. In addition to the participatory art pieces, the audience was invited to discuss their own experiences with noise in a workshop and in two talks, bringing together local residents and communities with experts on the effect of noise on health.

Encompassing the entire $5^{\text {th }}$ floor of Tate Modern, KIMA: Noise invited audiences to experience the 'ocean of urban sounds' surrounding them daily in a completely new way. Microphone stations captured sounds from Tate Modern's direct urban vicinity and streamed them in real-time as an immersive surround sound installation within Tate Exchange. Live city noises were analysed for their noise threshold and represented visually as a projection. Sonically, the sounds were distributed spatially through an ambisonic sound experience installation. The audience was invited to control the distribution of these sounds using a touch screen display.

Consciously becoming aware of the sources and the qualities of these sounds, the audience connected with urban noise in an all-new way, by experiencing sound arranged as immersive spatial audio-visual composition. Visitors were invited to 'draw' their own perceptions of sound, in the form of 'graphic scores' using the touchscreen interface, to then experience these representations as geometric soundscapes around them in the beautiful space of Tate Exchange.

A visual expression of sounds, also drawn from Tate Modern's urban environment was projected in the space on the gallery's windows. The projection allowed the audience to re-contextualise sound echoes from the background "white noise". Handing over a degree of control to the audience, Analema Group connected the annual theme of Tate Exchange programme, 'Power' to the subject of noise and its effect on health. The audience envisioned creative ways of dealing with noise in their own lives through active listening and participation in the talks, workshops and through the participatory art installation. The topic raises important questions on power, public influence and local governance. How much control do we have on noise exposure in the urban arena? How much awareness is there about the effect of noise pollution on local communities, their wellbeing and mental health? How can the public respond to these concerns? How much does awareness help to compensate impact on wellbeing in communities?

The art film KIMA: Noise completes the project with the interviews with experts, local residents and artists - sharing their experience of urban noise and creative strategies of dealing with its effects. The film continues the effort to raise awareness about urban noise and associated health issues with noise continuing to affect our mental health and wellbeing. KIMA: Noise asks specific questions around self-empowerment: How can we create a sensibility around urban noise through an immersive, participatory art installation and in collaboration with scientists? What is the role of art in communicating a range of personal and collective interventions? Can art be a vehicle in bringing scientists, artists, policy-makers and communities together to find creative solutions to this? The film includes interviews with visitors and local communities from both events - at Tate Exchange, and will now be screened in venues across London and online.

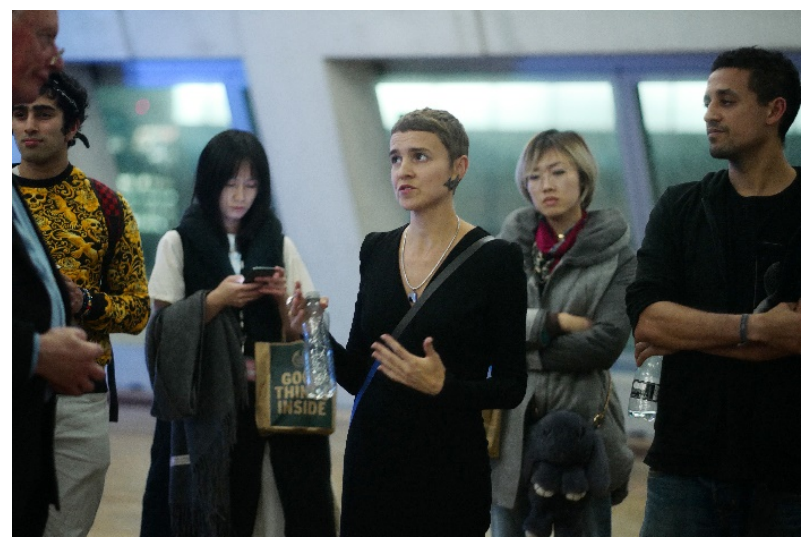

Figure 5: Evgenia Emets at KIMA: Noise image by Sophie le Roux (http://www.sophielerouxdocu.com).

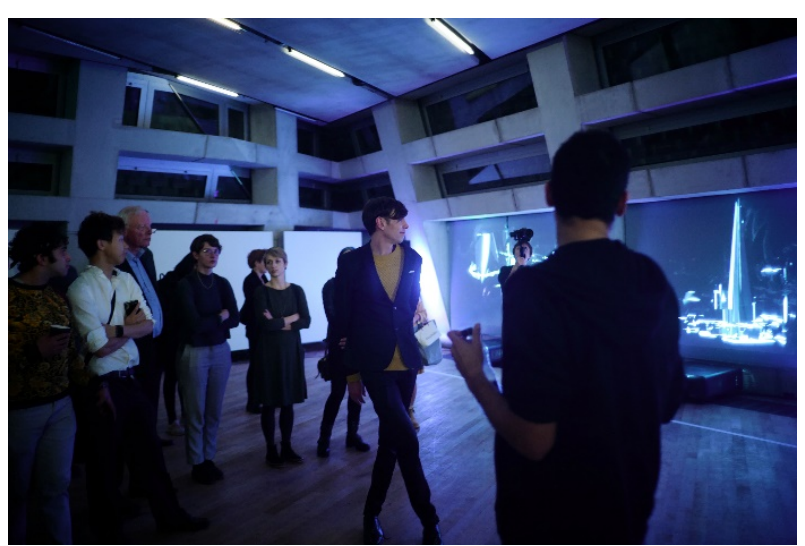

Figure 6: Oliver Gingrich at KIMA: Noise image by Sophie le Roux (http://www.sophielerouxdocu.com). 
The KIMA: Noise project shows how successful participatory art can be in bringing communities together with scientists, in providing a forum for exchange of experiences, narratives and ideas. In the case of KIMA: Noise, interest and support by local government was substantial: Mayor of London's Culture Team, Southwark Council, and Arts Council England supported the activity. Public Health England and DEFRA - Department of Environment, Food and Rural Affairs expressed their interest in the project and the amount of public support was unprecedented.

The project was carried by the members of the collective, the artists Evgenia Emets, Dr. Alain Renaud, David Negrao and Oliver Gingrich, as well as their supporters Paola D'Albore and Drucilla Burrell and received an enormous amount of support by companies (PRG UK, PSL Media group, Accucities), arts organisations (Soundtent.org, Southwark We Can, ACAVA), community groups (Plane Hell Action, Southwark Community, Culture, Health and Wellbeing Alliance, Noise Abatement Society), and scientists (Prof. Stephen Stansfeld, Queen Mary University of London, Michael Pluess, Queen Mary University of London, Ben Fenesch, Public Health England, Dr. Sara Payne, Lisa Lavia and many others.

Visited by more than 2,500 visitors in the space of Tate Exchange, and seen by many more online, in social media and flanked by various publications (EVA London 2019, EVA London 2020, KIMA: Noise monograph) the project succeeded in stimulating a vibrant debate on public noise.

\section{KIMA: VOICE}

KIMA: Voice is the second signature project by the Analema Group developed over several years. With a focus on the human voice, the artwork offers a space to explore vocal harmonies between audience members. Whereas previous projects focused on timbre (KIMA: The Wheel), frequency (KIMA: The Wave) or other sound parameters (KIMA at the Union Chapel), KIMA: Voice explores the space between voices, the concept of resonance, of harmonies between a multitude of voices (Gingrich, Ements, Renaud, Negrao 2019).

After initial project development and exhibition at ART IN FLUX (2018), By Other Means Gallery (2018), Digital Catapult (2018), the work was further developed to become more accurate and visually intuitive to perform with in a second round of development, premiered with Imperial College at the Great Exhibition Road Festival 2019. As one of the largest art festivals in London, Great Exhibition Road Festival sees over 60,000 people attending. The festival features 20 partners including the Science Museum, Natural History Museum, the Victoria and Albert Museum, and many others alongside Imperial College.

In conjunction with HEartS study, a study on 'Health, Economic and Social Impact of the Arts' by the Centre for Performance Science, a collaboration between Imperial College and Royal College of Music, Analema Group aimed to measure the impact of the participatory art installation through a mix of methods. The study organised in conjunction with researcher Ula Tympszuk at the Centre for Performance Science looked at a sample of 144 participants (72 pairs) consisting of 70 (48.6\%) women and 74 (51.4\%) men. A survey was facilitated before and after the experience, during which pairs of two were invited to explore harmonies between their voices to measure feelings of social connectedness, happiness, loneliness and feeling in tune with one another.

Table 1: KIMA: Voice engagement parameters, GERF 2019 data $n=144$, London, UK.

\begin{tabular}{lllll} 
& mean (SD) & median & min & max \\
\hline Number of harmonies & $5.49(3.68)$ & 5.5 & 0 & 19 \\
Duration of harmonies & $4.49(4.27)$ & 3.1 & 0 & 22.5 \\
Mean amplitude & $4.21(1.78)$ & 4.21 & 0.15 & 7.90 \\
\hline
\end{tabular}

Table 2: Experience scores, GERF 2019 data $n=144$, London, UK. The mean within-person change in experience scores before and after engagement with KIMA: Voice

\begin{tabular}{lllll}
\hline & $\begin{array}{l}\text { Before } \\
\text { mean (SD) }\end{array}$ & $\begin{array}{l}\text { After } \\
\text { mean (SD) }\end{array}$ & $\begin{array}{l}\text { Change } \\
\text { mean (SD) }\end{array}$ & p value \\
\hline Social connectedness (range 1-7) & $3.74(1.29)$ & $4.45(1.40)$ & $0.71(1.32)$ & $<0.001$ \\
Feeling in tune with others (range 1-7) & $4.34(0.91)$ & $4.85(0.90)$ & $0.51(1.06)$ & $<0.001$ \\
Happiness (range 1-7) & $5.25(0.75)$ & $5.52(0.77)$ & $0.27(0.60)$ & $<0.001$ \\
Loneliness (range 1-7) & $2.92(1.11)$ & $2.81(1.10)$ & $-0.11(1.23)$ & 0.25 \\
\hline
\end{tabular}


The mean age was 34.2 (SD 15.4), with the range of 16 to 74 years of age. KIMA: Voice measured three engagement parameters: number of harmonies achieved in a session, average duration (in seconds) of achieved harmonies and average amplitude of engagement (measured as amplitude/second/session duration).

The mean within-person change was: 0.71 for connection $(p<0.001), 0.51$ for feeling in tune $(p<0.001), 0.27 \quad(p<0.001)$ for happiness and no was no statistically significant change for feelings of loneliness before and after engagement. Although, there were no statistically significant associations between baseline experience scores and KIMA: Voice engagement parameters, the results show within-person change for social connection, for feeling in tune and for happiness. Measures were novel in that they including the recording of the duration of the interaction as well as the amount of harmonisations over time.

Compared to those who had no change in feeling in tune with others, participants who had a decrease or increase in their score achieved higher number of harmonies. Likewise, compared to those who had no change in happiness, participants who had a decrease in their happiness score achieved higher number of harmonies. Compared to those who had a decrease in feeling in tune with others, participants who had an increase in their score achieved higher mean amplitude (3.33 vs. 4.68, $p=0.003$ ). These results are relevant, in that they indicate both the potential as well as the difficulties in measuring participatory art.

Digital media and its use of data at the source, means that the potential to gather data during the process of the artistic experience is greater than ever. In the case of KIMA: Voice at Great Exhibition Road Festival, a significant sample size took part in the experience, and we were able to capture the effect of the art experience on participants. However, the idiom of social connectedness might have different connotations for different participants, and the impossibility to monitor any effect of the art piece on perceived loneliness (regarded as a long term mental health issue), shows that the potential of creative engagement to involve its audience can only ever reach so far.

Quantitative measures seem to only ever capture a median audience reaction, but struggle to grasp the wider picture of participatory arts' role as a contributor to public debate around important societal issues.

\section{CRITICAL ANALYSIS}

These four recent examples of successful contemporary participatory art works illustrate how these works can play a role in facilitating social connectedness among participants, local communities ( $A Y A H$ - Sign), and local institutions such as universities and schools (The Crack, KIMA Voice, KIMA Noise), arts organisations and governmental bodies (KIMA Noise, AYAH - Sign). The success of these projects lies in facilitating a wider discourse on relevant and prevalent societal topics such as pollution (The Crack), noise pollution (KIMA Noise) and social connectedness and mental health (KIMA: Voice).

The power of such projects lies in the direct engagement of the participants, the discursive role of the art work, their framing in workshops, talks and publications to assure that stakeholders think critically about subjects they are confronted with. Current academic and critical debate concentrates on the focus on measurable outputs, measurable societal benefits by funding bodies (Bishop 2012). The critique points to the limitations of measurable outputs through quantitative data in capturing the experiential, social and emotive response of stakeholders to participatory art.

\section{CONCLUSION}

With KIMA: Voice the research team consisting of the Analema Group and the Centre for Performance Science managed to capture quantitative data on the impact of collaborative art on happiness, feeling in tune with one another, and social connectedness, highlighting the potential of such art forms on personal perception of social cohesion. However only a mix of methods, including observations and interviews seem to capture a holistic image of societal benefit.

Detailed project reports, evaluation, and novel data capture methods all contribute to providing such a more in-depth understanding of the societal benefit of participatory art. A mix of triangulation, of research methods and quantitative and qualitative methodologies can provide a more multidimensional reflection on technology-facilitated art and its impact on wellbeing, mental health and social cohesion as well as awareness for important societal issues such as urban noise and pollution. 


\section{REFERENCES}

All Party Parliamentary Group on Arts, Health and Wellbeing Inquiry Report: Creative Health: The Arts for Health and Wellbeing. London July 2017.

Arts Council England (2018) Arts and culture in health and wellbeing and in the criminal justice system, a summary of evidence. Arts Council England. November 2018.
Bishop, C. (2012) Artificial Hells: Participatory Art and the Politics of Spectatorship. Verso books, London.

Gingrich, O., Emets, E., Renaud A., and Negrao, D. (2019) KIMA: Noise: A visual sound installation on urban noise. EVA London 2019 (Electronic Visualisation and the Arts).

Gingrich, O., Tymoszuk, U., Emets, E., Renaud, A., and Negrao, D (2019) KIMA: The Voice. EVA London 2019 (Electronic Visualisation and the Arts). 